\title{
Expanded gold standard in the diagnosis of Chlamydia trachomatis in a low prevalence population: diagnostic efficacy of tissue culture, direct immunofluorescence, enzyme immunoassay, PCR and serology
}

Henning Thejls, Judy Gnarpe, Håkan Gnarpe, Per-Göran Larsson, Jens-Jörgen PlatzChristensen, Lars Östergaard, Arne Victor,

\begin{abstract}
Objective-To evaluate the diagnostic efficacy of chlamydia culture, direct immunofluorescence (DFA), direct enzyme immunoassay (EIA), polymerase chain reaction (PCR) and serology by defining positive culture or at least two positive non-culture tests as true positive. Setting-Three gynaecological departments located in separate areas of Sweden.
\end{abstract}

Patients and Design-All pregnant women requesting abortion during a six month period were included. In cases with unconfirmed non-culture tests, reculture with multiple passage and PCR on the culture transport medium was performed for confirmation. Serum was analysed for chlamydial antibodies type IgG, IgM and IgA using microimmunofluorescence.

Results-18 of 419 (4.3\%) patients were positive for chlamydia according to the defined criteria. Twelve of 419 (2.9\%) were positive in standard culture (primary inoculation). The sensitivity of standard culture, DFA, EIA and PCR were $66.7 \%, 77 \cdot 8 \%, 64.7 \%$ and $71.4 \%$ respectively. The specificity $100 \%$ (by definition), $99.5 \%, 100 \%, 100 \%$ respectively. The positive predictive value $100 \%$ (by definition), $87.5 \%, 100 \%, 100 \%$ respectively. Negative predictive value 98.5\%, 99.0\%, 98.5\%, 98.9\% respectively. Serum IgG titre of $\geq 64$ and $\geq 1024$ gave positive predictive values of $10 \%$ and $21 \%$ respectively.

Conclusions-When an expanded gold standard is used, the specificity and positive predictive value of the non-culture tests used are comparable with that of standard culture even in this low prevalence population. Standard culture underestimated the chlamydia prevalence by $33 \%$. The prevalence found represents a decrease from 10 to $2.9 \%$ of culture verified chlamydia during four years in comparable populations. Chlamydial antibodies of certain immunological classes are not necessarily present in cases with chlamydia.

(Genitourin Med 1994;70:300-303)
Introduction

The sensitivity of chlamydia tissue culture from single cervical swabs has been reported to be from $33 \%$ to $86 \% .^{1}$ Although the lowest reported sensitivities probably can be ascribed to suboptimal specimen sampling and handling a sensitivity of more than $70-80 \%$ is not to be expected in routine culture using single cervical swabs. ${ }^{2}$ The prevalence of chlamydia infections is thereby underestimated leading to suboptimal epidemiologic control. The use of culture as a reference against which other tests are evaluated may also distort the interpretation of new tests.

A low positive predictive value and specificity of a new test using culture as a reference can result from a low sensitivity of the culture method. The validity of new tests can thereby be underestimated.

Some studies indicate that recently acquired infections shed more infectious units than older infections and are therefore more likely to have positive cultures. ${ }^{13}$

The proportion of chronic "old" infections with low infection burdens might be higher in low prevalence populations than in high risk/ high prevalence populations. ${ }^{4}$ This may reduce the sensitivity of culture in low prevalence populations but should reduce even further the sensitivity of other tests. The evidence for a significant difference in sensitivity of culture and antigen detection tests between low and high prevalence populations is however weak. ${ }^{56}$

The problem of "false positive tests" is inherent to the non culture tests as the specificity is not $100 \%$. They should therefore preferably be confirmed by another test of a different profile to safely establish the diagnosis when positive cultures cannot be obtained.? The tissue culture is still the most specific test for Chlamydia trachomatis although false positive culture results can occur in routine laboratory work. ${ }^{8}$

The purpose of this study was to evaluate the diagnostic precision of routine culture and three non-culture tests in a population with expected low prevalence using a defined expanded gold standard. We also wanted to evaluate the diagnostic significance of serological tests in this population. 


\section{Material and methods}

Four hundred and twenty three consecutive pregnant women seeking abortion during a six month period at three gynaecological departments were included in a prospective study. History of prior infection with Chlamydia trachomatis was recorded.

\section{Sample procedure}

Blood samples for determination of humoral antibodies to Chlamydia trachomatis were obtained from all patients. The cervix was cleansed with a large swab. The first cotton swab in the test set for Direct Enzyme Immunoassay (EIA) (MicroTrak, SYVA, Palo Alto, CA) was used for endocervical sampling and placed in a solution of Proteinase $K$ to be frozen and later tested with PCR technique. The second swab from the test set was used according to the manufacturer's instructions for the EIA test. A cotton-tipped aluminum swab was used for Direct Immunofluorescent assay (DFA) test (MicroTrak, SYVA, Palo Alto, CA); after drying, the slide was fixed with $96 \%$ ethanol. The swab was then placed in 2SP transport media and sent to the laboratory the same day for culture. If culture was not immediately performed, the specimen was either placed in the refrigerator at $+4^{\circ} \mathrm{C}$ overnight or frozen at $-70^{\circ} \mathrm{C}$.

Cultures were performed by the local bacteriological laboratories of the three hospitals involved in the study using their standard method for clinical routine: in Gävle $300 \mu \mathrm{l}$ of the 2SP medium was inoculated on monolayers of cycloheximide treated McCoy cells in 24-wells plates and centrifuged at $1800 \mathrm{~g}$ for one hour at $35^{\circ} \mathrm{C}$. Staining was done with fluorescein isothiocyanide conjugated monoclonal antibodies (SYVA, Palo Alto, CA) after 48 hours of incubation. In Skövde $500 \mu 1$ were added to glass vials with monolayers of McCoy cells on coverslips of $12 \mathrm{~mm}$. The vials were centrifuged at $3000 \mathrm{~g}$ for one hour. After incubation for 2 hours, RPMI medium was replaced by RPMI including cycloheximide, incubated for 72 hours and stained with iodine. In Göteborg $500 \mu 1$ were added to 24-well plates containing monolayers of irradiated McCoy cells, centrifuged and incubated for 72 hours and then stained with iodine.

All EIA and DFA tests from Göteborg and Gävle were done at the Department of Clinical Bacteriology, Gävle Central Hospital. The DFA slides were read independently by two observers. There were slight differences in the exact number of EBs on the positive slides between the two observers but full agreement concerning positive and negative slides.

The third centre in Skövde was responsible for running their own tests. All serological tests from the three centres were done in Gävle, using an indirect microimmunofluorescence test (MIF) based on egg cultured elementary bodies from Chlamydia trachomatis, serovars D-K. ${ }^{9}$ All sera were tested for IgG, IgM and IgA antibodies.

Samples for PCR were obtained with EIA swabs as described above. The swab was placed in a microtube with $0.5 \mathrm{ml}$ transport medium containing $200 \mu \mathrm{g}$ of proteinase $\mathrm{K}$ per $\mathrm{ml}, 10 \mathrm{mM}$ Tris buffer and $1 \mathrm{mM}$ EDTA. The samples were stored at $-20^{\circ} \mathrm{C}$ until processed. The microtubes containing patient samples were incubated at $37^{\circ} \mathrm{C}$ for $30 \mathrm{~min}$ and subsequently incubated at $98^{\circ} \mathrm{C}$ for 10 $\mathrm{min}$. The tubes were hereafter centrifuged at $10000 \mathrm{~g}$ for $30 \mathrm{~min}$ at $4^{\circ} \mathrm{C}$ and $38.5 \mu 1$ of supernatant was used for PCR.

The primers used were 5'CGCATGCAAGATATCGAGTATGCGTTGTTAGG-3' and 2: 5'GACCGGCCTCTAGCGCTGCG3' amplifying a $473 \mathrm{bp}$ fragment of the Chlamydia trachomatis plasmid. PCR was carried out in a total volume of $50 \mu 1$ consisting of $38.5 \mu \mathrm{l}$ supernatant of patient sample, $10 \mu \mathrm{l}$ buffer (250mM KCL, 50mM Tris pH 8.4, $12.5 \mathrm{mM} \mathrm{MgCl}_{2}, 0.1 \mathrm{mg}$ of gelatin per ml) and $1.5 \mu \mathrm{m}$ of each primer and 1 unit $/ 50 \mu \mathrm{l}$ Ampl-Taq DNA Polymerase (Perkin Elmer). A temperature of $94^{\circ} \mathrm{C}$ was kept for 1 minute, followed by 40 cycles each including $1 \mathrm{~min}$ at $94^{\circ}, 2 \mathrm{~min}$ at $55^{\circ}$ and $3 \mathrm{~min}$ at $72^{\circ}$. Finally the specimens were incubated at $72^{\circ} \mathrm{C}$ for ten minutes and electrophorised on a 3\% agarose gel and visualised using UV light after ethidium bromide staining. ${ }^{10}$

In cases of unconfirmed non-culture tests the remainder of the original saved 2SP media, frozen at $-70^{\circ} \mathrm{C}$, was recultured using multiple passages and tested with a different PCR method according to Wahlberg et al ${ }^{11}$ at the Department of Clinical Microbiology, Akademiska Sjukhuset, Uppsala University, Uppsala. The primers used were RIT 23: 5'GCA ATG GTT TCT TAC TGT GGA and RIT 24: 5'AGG AGT TTG TGC TCT TAC TAG, ${ }^{12}$ amplifying a 318 bp fragment from the genom encoding for cysteine rich outer membrane protein.

The criteria used in this study for accepting a test as true positive (expanded gold standard) was: 1) Positive standard culture (primary inoculation). 2) One positive non-culture test, confirmed by culture after multiple passage. 3) One positive non-culture test confirmed by at least one of the other non-culture tests. 4) Positive PCR test confirmed by a different PCR method using different primers, applied on the 2SP transport medium and performed by another laboratory.

\section{Statistical methods}

Using the above mentioned criteria for an infected person the calculation of the sensitivity, specificity, positive predictive value (PPV) and negative predictive value (NPV) for each diagnostic method was based on the number of specimens with the test where at least two other tests had been obtained.

\section{Results}

Samples for culture, at least two non-culture tests and serology were obtained from 419 of 423 consecutive patients. PCR tests were missing in 38 of 419 patients owing to 
Table 1 Age related prevalence of chlamydia diagnosed by positive culture or at least two positive non-culture tests.

\begin{tabular}{lrcl}
\hline Age (years) & $N$ & Chlamydia & Prevalence (\%) \\
\hline$<20$ & 61 & 2 & $3 \cdot 27$ \\
$20-24$ & 114 & 4 & $3 \cdot 50$ \\
$25-29$ & 115 & 6 & $5 \cdot 21$ \\
$30-34$ & 64 & 3 & $4 \cdot 68$ \\
$\geq 35$ & 65 & 3 & $4 \cdot 61$ \\
Total & 419 & 18 & $4 \cdot 30$ \\
\hline
\end{tabular}

Table 2 Results of culture, DFA* test, Direct ELAf-test and $P C R \neq$ in 18 patients evaluated as chlamydia positive and two patients with unconfirmed non-culture tests

\begin{tabular}{|c|c|c|c|c|c|}
\hline Patient & Culture & $\begin{array}{l}D F A \\
\text { no } E B s \|\end{array}$ & $E I A$ & $P C R$ & $\begin{array}{l}\text { MIFß } \\
\text { titre of } \\
\text { IgG/IgM/IgA }\end{array}$ \\
\hline 9 & + & $>250$ & + & - & $256 / 0 / 0$ \\
\hline 66 & + & $>200$ & + & + & $32 / 0 / 16$ \\
\hline 74 & + & $>250$ & + & + & $256 / 0 / 0$ \\
\hline 105 & + & 0 & + & $n d^{\star \star}$ & $1024 / 0 / 0$ \\
\hline 125 & + & 81 & - & nd & $256 / 0 / 16$ \\
\hline 168 & + & 0 & + & + & $256 / 0 / 0$ \\
\hline 181 & + P4tt & 7 & - & - & $0 / 0 / 0$ \\
\hline 185 & - & 0 & - & $+1+\$ \S$ & $256 / 0 / 0$ \\
\hline 189 & - & 7 & - & $-1+$ & $256 / 0 / 0$ \\
\hline 215 & + & 55 & nd & + & $1024 / 0 / 16$ \\
\hline 221 & $+\mathrm{p} 4$ 拉 & 2 & - & nd & $1024 / 0 / 16$ \\
\hline 252 & + & $>100$ & + & + & $32 / 0 / 0$ \\
\hline 283 & + & $>100$ & + & nd & $512 / 0 / 0$ \\
\hline 337 & + & 0 & - & - & $0 / 0 / 0$ \\
\hline 344 & + & $>100$ & + & + & $128 / 0 / 0$ \\
\hline 376 & - & $>100$ & + & + & $128 / 32 / 0$ \\
\hline 395 & - & $>100$ & + & + & $64 / 0 / 0$ \\
\hline 421 & + & $>100$ & + & + & $32 / 32 / 16$ \\
\hline 191 & - & 2 & - & $-1-$ & $256 / 0 / 0$ \\
\hline 199 & - & 13 & - & $-1-$ & $0 / 0 / 0$ \\
\hline
\end{tabular}

*Direct Immunofluorescent assay. †Enzyme immunoassay. $\ddagger$ Polymerase Chain Reaction. \&Microimmunofluorescence Technique for detection of chlamydial serum antibodies. Technique for detection of chlamydial serum antibodies.
॥Chlamydial elementary bodies. ${ }^{\star}$ Not done. $\neq \neq C$ Culture positive only after four passages in tissue culture. \$\$PCR positive in two different specimens analyzed at different laboratories using different primers.

mishaps during transportation.

The age distribution of the patients and the age stratified chlamydia prevalence using the expanded gold standard is shown in table 1. The prevalence for the three centres using the gold standard was $8 / 140(5 \cdot 7 \%), 5 / 134$ (3.7\%) and $5 / 145(3 \cdot 4 \%)$ for Gävle, Skövde and Göteborg respectively.

Eighteen patients met the criteria for confirmed chlamydia infection and two additional

Table 3 Sensitivity, specificity, positive predictive value (PPV) and negative predictive value (NPV) of tissue culture (TC), direct immunofluorescence antibody test (DFA) with cut-off >10 EBs, DFA without cut-off (one or more EBs), Direct enzyme immunoassay $(E L A)$ and polymerase chain reaction (PCR) when compared with reference*

\begin{tabular}{llllll}
\hline & $\begin{array}{l}\text { Sensitivity } \\
(\%)\end{array}$ & $\begin{array}{l}\text { Specificity } \\
(\%)\end{array}$ & $\begin{array}{l}\text { PPV } \\
(\%)\end{array}$ & $\begin{array}{l}\text { NPV } \\
(\%)\end{array}$ & $\begin{array}{l}\text { Number of } \\
\text { Specimenst }\end{array}$ \\
\hline TC $(\geq 10 \mathrm{EBs})$ & $61 \cdot 7$ & $100 \ddagger$ & $100 \ddagger$ & $98 \cdot 5$ & 419 \\
DFA & $61 \cdot 1$ & $99 \cdot 8$ & $91 \cdot 7$ & 98.3 & 419 \\
DFA $(\geq 1 \mathrm{EBs})$ & $77 \cdot 8$ & 99.5 & 87.5 & $99 \cdot 0$ & 419 \\
EIA & $64 \cdot 7$ & 100 & 100 & 98.5 & 418 \\
PCR & $71 \cdot 4$ & 100 & 100 & 98.9 & 381 \\
\hline
\end{tabular}

^Reference defined as positive culture in any passage number or at least two positive non-culture tests. $†$ Number of patients where the test has been taken together with culture and at least one non culture test. $\ddagger$ Defined as $100 \%$.

Table 4 Sensitivity, specificity, positive predictive value (PPV), a negative predictive value (NPV) oftissue culture, direct immunofluorescence antibody test (DFA) (one or more EBs), Direct enzyme immunoassay (ELA) and polymerase chain reaction (PCR) when compared with routine culture

\begin{tabular}{llllll}
\hline & $\begin{array}{l}\text { Sensitivity } \\
\%\end{array}$ & $\begin{array}{l}\text { Specificity } \\
\%\end{array}$ & $\begin{array}{l}P P V \\
\%\end{array}$ & $\begin{array}{l}\text { NPV } \\
\%\end{array}$ & $\begin{array}{l}\text { Number of } \\
\text { Specimens }\end{array}$ \\
\hline DFA & 75.0 & 98.3 & 56.3 & 99.3 & 419 \\
EIA & 81.8 & 99.5 & 81.8 & 99.5 & 418 \\
PCR & 77.8 & 99.2 & 70.0 & 99.5 & 381 \\
\hline
\end{tabular}

patients had a single unconfirmed positive non-culture test. The results of all tests and serology for each patient are summarised in table 2 . It should be noted that the two cases with $>100$ EBs, positive in EIA and PCR but negative in culture came from one centre using iodine as staining method known to be less sensitive that immunofluorescence.

Previously diagnosed and treated chlamydia infection was reported by four of $18(22 \%)$ patients with current infection and by 86 of $401(21 \%)$ patients without current chlamydia infection.

The sensitivity, specificity, predictive value positive (PPV) and predictive value negative (NPV) of each test is shown in table 3 using the expanded gold standard as reference. The corresponding values if routine culture had been used as reference are shown in table 4 for comparison.

Serology

A titre of serum IgG of $\geq 64$ was found in 125 $(29.8 \%)$ of 419 patients. Thirteen of the eighteen chlamydia positive patients had titres of $\geq 64$ giving sensitivity, specificity, PPV and NPV of 72, 72, 10 and 98 respectively. The effect of higher cut-off values are illustrated in table 5. Serum IgM $\geq 16$ was found in 16 patients of which two were positive for chlamydia and serum $\operatorname{IgA} \geq 16$ were found in 68 patients of which five had chlamydia (table 2). Two patients with positive cultures were negative in all serological tests.

Polymerase Chain Reaction (PCR):

PCR was performed primarily in 381 patients. Ten patients were positive by PCR. Six of these had a positive tissue culture, three had $>100$ chlamydial elementary bodies (EBs) in the DFA test and a positive EIA test, and one was negative in all other tests but had a positive IgG titre of 256 (table 2) and was confirmed by a different PCR test run in Uppsala on the 2SP transport medium.

\section{$D F A$}

Twelve patients had 10 or more EBs per slide and three patients had between two and nine EBs. Two patients with EBs and negative culture had recently been treated with penicillin $\mathrm{V}$ for respiratory tract infection. Three patients with no EBs had positive cultures.

\section{$E L A$}

The direct EIA test was positive in 10 patients. All were confirmed by two or more of the other tests giving a specificity and PPV

Table 5 The sensitivity, specificity, positive predictive value (PPV) and negative predictive value (NPV) for detecting chlamydia positive cases by serum IgG at different titre levels among 419 patients

\begin{tabular}{llllll}
\hline Titre & $\begin{array}{l}\text { Sensitivity } \\
(\%)\end{array}$ & $\begin{array}{l}\text { Specificity } \\
(\%)\end{array}$ & $\begin{array}{l}P P V \\
(\%)\end{array}$ & $\begin{array}{l}\text { NPV } \\
(\%)\end{array}$ & $N$ \\
\hline$\geq 64$ & 72 & 72 & 10 & 98 & 125 \\
$\geq 128$ & 67 & 82 & 13 & 98 & 83 \\
$\geq 256$ & 50 & 89 & 17 & 98 & 52 \\
$\geq 512$ & 22 & 95 & 17 & 96 & 24 \\
$\geq 1024$ & 17 & 97 & 21 & 96 & 14 \\
\hline
\end{tabular}


of $100 \%$. Three patients with positive culture were negative in the EIA test; two of these had no EBs in the DFA test (table 2). In one (patient 125) only one inclusion was found in tissue culture. The DFA test was positive ( 81 EBs) and EBs were found even in the EIA medium and in the 2 SP medium.

\section{Discussion}

The chlamydia prevalence in this study group was unexpectedly low. Four years earlier a comparable population from the same three centres showed a prevalence of $10 \%$ diagnosed by tissue culture alone. ${ }^{13}$ A similar decline in prevalence have been reported in pregnant women at prenatal clinics. ${ }^{14}$ The general decline of the number of positive chlamydia cultures as reported by the Swedish health authorities seems therefore to be a true decline in prevalence and not a result of retesting prior treated persons. The decline in prevalence is probably a result of early screening programs and public health information programme.

Although the few cases positive for chlamydia in our study calls for caution in generalising the results some important points can be made.

In low prevalence populations the positive predictive value decreases rapidly with specificity. This is a mathematical relationship which presumes that sensitivity is an intrinsic property of the test and therefore independent of the population tested. ${ }^{15}$ All EIA and PCR tests were confirmed in this study giving a PPV of $100 \%$ of both tests but the sensitivity was only $64 \cdot 7 \%$ and $71 \cdot 4 \%$ respectively. If we had evaluated the test using standard culture as reference the sensitivity of the EIA and PCR test should have been $81 \cdot 8 \%$ and $77 \cdot 8 \%$ respectively but the PPV only $81.8 \%$ and $70 \%$ respectively (table 4). A corresponding effect on the PPV of broadening the gold standard has been demonstrated by Jang et $a l^{16}$ in a high prevalence male population testing a chemiluminometric immunoassay.

The interpretation of the DFA test using a certain number of EBs as a cut-off has been questioned by some authors. ${ }^{17}$ Our results show that regarding slides with any number of EBs as positive, the DFA test is the most sensitive single test in our study $(78 \%)$ still having a specificity of more than $99 \%$.

Single serological tests are considered of little value in the diagnosis of current infection. ${ }^{4}$ This is confirmed by our study (table 5). A high titre of serum antibodies has no value in predicting positive culture or antigen test from the cervix having a PPV of only $21 \%$ for titres $\geq 1024$. Even more important is to stress that negative serology does not exclude the existence of chlamydia infection.

In conclusion the results of this study show that the specificity and especially the PPV of non culture tests are strongly underestimated if culture is used as reference. We therefore suggest that new tests should be evaluated by an expanded gold standard based on multiple tests, each with proven high specificity and sensitivity.

The authors thank Bernt Claesson, M.D. Ph.D., Department of Clinical Bacteriology in Skövde and Carl Påhlsson, Ph.D., Department of Clinical Bacteriology in Uppsala for excellent laboratory work.

1 Kellog JA. Clinical and laboratory considerations of culture vs antigen assays for detection of Chlamydia trachomatis from genital specimens. Arch Pathol Lab Med chomatis from gen

2 Barnes RC. Laboratory diagnosis of human chlamydial infections. Clin Microbiol Rev. 1989;2:119-36.

3 Brunham RC, Kuo C-C, Cles L, Holmes KK. Correlation of host immune response with quantitative recovery of Chlamydia trachomatis from the humane endocervix. Infect Immun 1983;39:1491-4

4 Gann PH, Herrmann JE, Candib L, Hudson RW. Accuracy of Chlamydia trachomatis antigen detection methods in a low prevalence population in a primary care setting. F Clin Microbiol 1990;28:1580-5.

5 Taylor-Robinson D, Thomas BJ. Laboratory techniques for the diagnosis of chlamydial infections. Genitourin Med 1991;67:256-66.

6 Thomas BJ, Osborn MF, Munday PE, Evans RT, TaylorRobinson D. A 2-year quantitative assessment of Chlamydia trachomatis in a sexually transmitted disease clinic population by the MicroTrak direct smear immunofluorescence test. Int $\mathcal{f}$ STD AIDS 1990;1: immuno 7 .

7 Schachter J, Stamm WE, Chernesky MA, et al. Nonculture tests for genital tract chlamydial infection. What does the package insert mean, and will it mean the same thing tomorrow? (Ed.) Sex Trans Dis 1992;19:243.

8 Rettig PJ. Chlamydial infections in pediatrics: Diagnostic and therapeutic considerations. Pediatr Infect Dis 1986; 5:158-62.

9 Treharne JD, Darougar S, Jones BR: Modification of the micro-immunofluorescence test to provide a routine serodiagnostic test for chlamydial infections. $\mathcal{f}$ Clin Pathol 1977;30:510.

10 Østergaard L, Traulsen J, Birkelund S, Christiansen G. Evaluation of urogenital Chlamydia trachomatis infections by cell culture and the polymerase chain reaction tions by cell culture and the polymerase chain reaction using a closed sys

11 Wahlberg J, Lundeberg J, Hultman $T$, Uhlén $M$. General colorimetric method for DNA diagnostics allowing direct solid-phase genomic sequencing of the positive samples. Proc Natl Acad Sci 1990;87:6569-73.

12 Clarke IN, Ward ME, Lambden PR. Molecular cloning and sequence analysis of a developmentally regulated cysteine-rich outer membrane protein from Chlamydia trachomatis. Gene 1988;71:307-14.

13 Larsson P-G, Platz-Christensen J-J, Thejls H, Forsum U, Påhlson C. Incidence of PID following first trimester legal abortion in women with bacterial vaginosis after treatment with metronidazole; a double-blind rantreatment with metronidazole; a double-blind ran-

14 Thejls H, Gnarpe J, Gnarpe H, Larsson G. Age related decrease in prevalence of Chlamydia trachomatis among pregnant women. Sex Trans Dis, 1991;18:137.

15 Dierksheide WC. Medical Decisions: Interpreting clinical tests. Am Soc Microbiol 1987;53:677-80.

16 Jang D, Sellors JW, Mahony JB, Pickard L, Chernesky MA. Effects of broadening the gold standard on the performance of a chemiluminometric immunoassay to detect Chlamydia trachomatis antigens in centrifuged first void urine and urethral swab samples from men. $S e x$ Transm Dis 1992;19:315-9.

17 Stacy C, Munday P, Thomas B, Gilchrist C, TaylorRobinson D, Beard R. Chlamydia trachomatis in the fallopian tubes of women without laparoscopic evidence of salpingitis. Lancet 1990;336:960-3. 